\title{
12 Saline Agriculture as a Way to Adapt to Sea Level Rise
}

Pier Vellinga and Edward G. Barrett-Lennard

\section{CONTENTS}

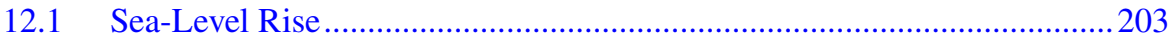

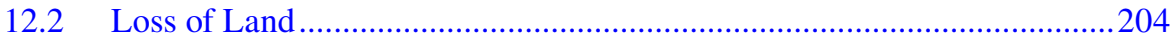

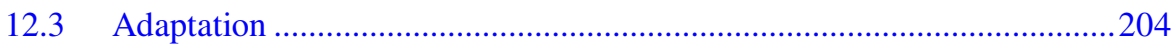

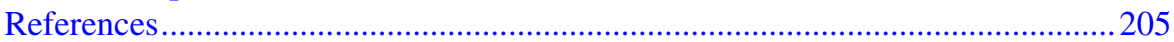

Historically the experimental production of food under saline soil conditions has been focused on dryland systems where water shortages and salinization go hand in hand. Recently water-rich delta areas have started facing similar salinization challenges. Millions of hectares of fertile coastal lands and related livelihoods maybe lost as a result of climate change, accelerated sea level rise and an increase in extreme sea level events. The chapters in the following section describe the state of the art on salinization and saline agriculture experiments in delta areas.

Our focus has been primarily on the European North Sea countries and on Bangladesh with articles describing the typical delta characteristics and ongoing experiments including stakeholder's perceptions. However, the issues raised in these case study areas can be expected to be experienced in all low-lying coastal areas. The section also includes a case study on saline food production for tourists on a small low-lying island. Most of the articles focus on well-known crops such as potatoes, rice, grains, and vegetable crops, while major opportunities may also be found in combinations of crops and fish or in fiber, fodder, or products derived from seaweeds or mangroves. Regarding saline agriculture in delta areas, research and testing is still in the early stages. However, the challenge is clear given the global projections of sea-level rise.

\subsection{SEA-LEVEL RISE}

Projections of global average sea-level rise published by the Intergovernmental Panel on Climate Change (IPCC 2019) present a range from $0.4 \mathrm{~m}$ to $1.0 \mathrm{~m}$ for 2100. However, there are scenarios developed by individual researchers that predict far higher levels of sea-level rise (up to $2 \mathrm{~m}$ or more) by the year 2100 (DeConto \& Pollard 2016). 
Over the last few decades sea-level rise has accelerated from $1.4 \mathrm{~mm}$ per year over the period 1901-1990, to $\sim 3.6 \mathrm{~mm}$ per year over the years 2006-2015 (IPCC 2019). At a regional level there are significant differences in rates of sea level rise because of natural variability in oceanic circulation and the rebalancing of the ocean surface in response to changes in geo-gravitational forces (caused by melting ice caps) (IPCC 2019).

\subsection{LOSS OF LAND}

Sea-level rise and changes in extreme sea-levels will have major implications for land in low-lying coastal areas and river deltas. Salt intrusion in river delta's is very likely, not only as a result of sea-level rise, but also as a consequence of changes in river regimes, upstream dam building and subsequent sediment interception in rivers feeding the deltas as described by Sepehr Eslami et al., for the Mekong Delta (Eslami et al. 2019).

Nicholls et al. (2011) made an estimate of the area of land loss due to regular flooding. Under conditions of no-adaptation to climate change, they have estimated land losses by 2100 of 877,000 and $1,789,000 \mathrm{~km}^{2}$ for a 0.5 and $2.0 \mathrm{~m}$ rise in sealevel, respectively (Figure 12.1). This amounts to $\sim 0.6$ and $1.2 \%$ of global land area. The net population displaced by this rise is estimated to be 72 and 187 million people respectively over the century (roughly $0.9-2.4 \%$ of the global population) (Nicholls et al. 2011).

\subsection{ADAPTATION}

Communities and countries are likely to protect their land and settlements from flooding. In fact, this has been done for hundreds of years in the North Sea countries. However, diking and draining can be expected to trigger an almost irreversible

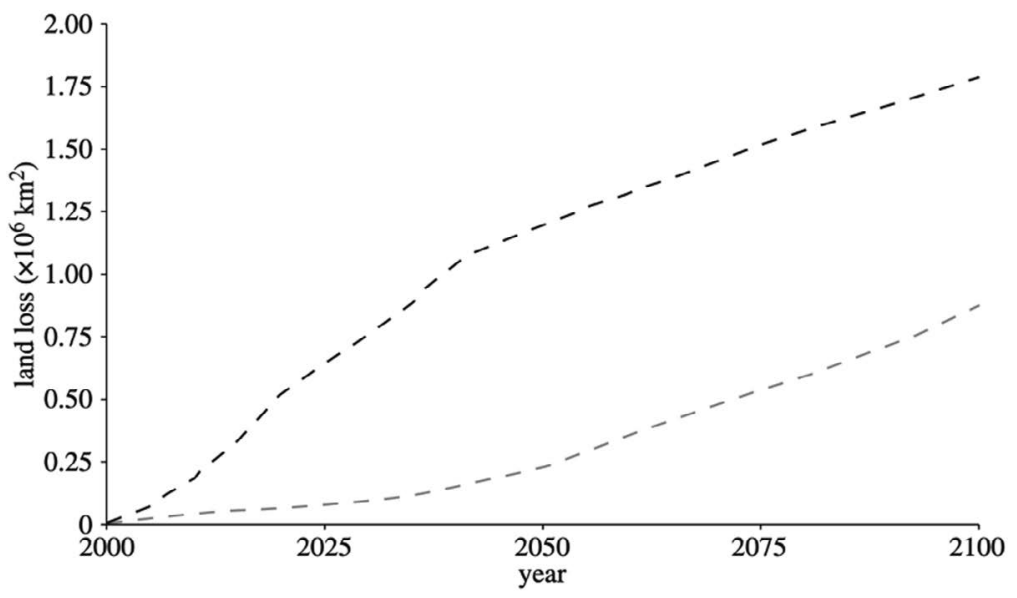

FIGURE 12.1 Global dryland losses assuming no adaptation for a $0.5 \mathrm{~m}$ (grey line) or $2 \mathrm{~m}$ (black line) rise in sea-level by 2100 as estimated by Nichols et al. (2011). 
process of land subsidence and therefore the need for further dike heightening. This sequence is the reason why major parts of the agricultural coastal lands around the North Sea are now situated below mean sea-level (Chapter 13 of this book). Although higher dikes provide protection from flooding, for many geological situations they will not prevent an increase in underground saline water seepage into the low-lying agricultural areas. Once field levels are below mean sea-level it will become increasingly difficult to keep the saline water away from the agricultural soils. For this reason, coastal famers, waterboards and governments in the North Sea countries are beginning to explore a range of adaptation options including the creation of fresh water buffers and the introduction of crops and agricultural and water management practices that will allow production under saline soil and water conditions (Chapter 14 of this book).

The North Sea countries protected by dikes are now starting to explore these issues and opportunities. At the same time deltas with little or no dike protection and some experience in agriculture under brackish conditions are now also exploring their options. One way or another, all coastal areas, river deltas and small islands will need to adapt to rising sea-levels and changes in river regimes, storm regimes and sediment supply. This section presents the start of this process.

\section{REFERENCES}

Beauchampet, I. C. 2021. "Stakeholder Perspectives on the Issue of Salinization in Agriculture in The Netherlands." In Future of Sustainable Agriculture in Saline Environments. London: Routledge.

DeConto, R. M., \& Pollard, D. 2016. Contribution of Antarctica to past and future sea-level rise. Nature, 531(7596), 591-597.

Eslami, S., Hoekstra, P., Trung, N. N., Kantoush, S. A., Van Binh, D., Quang, T. T., \& van der Vegt, M. 2019. Tidal amplification and salt intrusion in the Mekong Delta driven by anthropogenic sediment starvation. Scientific reports, 9(1), 1-10.

IPCC, 2019: Summary for Policymakers. In: IPCC Special Report on the Ocean and Cryosphere in a Changing Climate. [H.O. Pörtner, D.C. Roberts, V. MassonDelmotte, P. Zhai, M. Tignor, E. Poloczanska, K. Mintenbeck, A. Alegría, M. Nicolai, A. Okem, J. Petzold, B. Rama, N.M. Weyer (eds.)]. In Press.

Nicholls, R. J., Marinova, N., Lowe, J. A., Brown, S., Vellinga, P., De Gusmao, D., ... \& Tol, R. S. 2011. Sea-level rise and its possible impacts given a 'beyond $4 \mathrm{C}$ world' in the twenty-first century. Philosophical transactions of the Royal Society A: mathematical, physical and engineering sciences, 369(1934), 161-181.

Vries, M. de, Velstra, J., Medenblik, J., Jansen, J., Smit, L., Rispens, A., \& Essink, G. O. 2021. "Mitigating and Adapting Agriculture of Coastal Areas in the Netherlands Wadden Sea Region to Increasing Salinization: From a Vision towards a Practical Implementation." In Future of Sustainable Agriculture in Saline Environments. London: Routledge. 


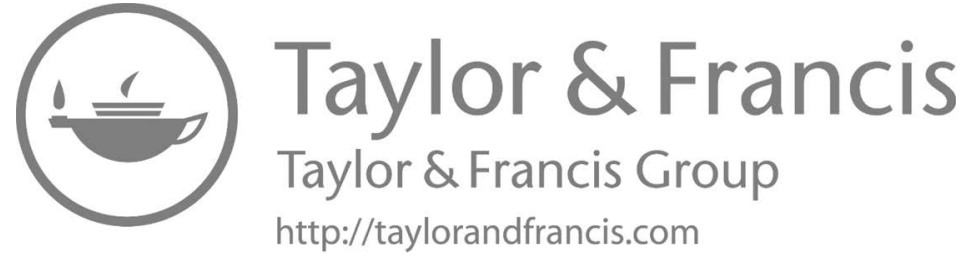

